\title{
Psychobiological and Evolutionary Perspectives on Coping and Health Characteristics Following Loss: A Twin Study
}

\author{
Nancy L. Segal' and Shelley A. Blozis ${ }^{2}$ \\ 'Department of Psychology, California State University, Fullerton, USA \\ ${ }^{2}$ Department of Psychology, University of California, Davis, USA
}

\begin{abstract}
A $n$ analysis of coping, grief and health characteristics is reported for a bereaved monozygotic (MZ) and dizygotic (DZ) same-sex twin sample. The data were examined with reference to psychobiological and evolutionary perspectives on behavior. A Coping Scale, included as part of a comprehensive Twin Loss Survey (TLS), assessed coping with daily responsibilities and activities 1-2 months before the co-twin's death, 1-2 months following the co-twin's death and currently. A Grief Intensity Scale obtained judgments of grief 1-2 months following the loss, and currently. Information on physical symptoms was available from the Somatization Scale of the Grief Experience Inventory. Psychobiological and evolutionary perspectives specified hypotheses for two twin groups: one model was specified to reflect bereavement experiences immediately following loss of the co-twin (retrospective twin group); a second model represented present bereavement response (current twin group). Consistent with psychobiological theory, twins' social closeness showed a positive association with grief intensity which, in turn, affected somatic symptoms and coping efficacy in predicted directions. With respect to evolutionary psychological theory, the effect of zygosity on current grief implicated correlates of genetic relatedness as factors in the bereavement process.
\end{abstract}

Factors influencing coping and health characteristics following the loss of a close relative are of interest (Folkman, 1997). Specification of hypotheses and interpretation of findings have, however, not always been made in the context of a theory of bereavement. The present study applied psychobiological and evolutionary perspectives in a twin analysis of individual differences in coping and healthrelated characteristics associated with loss. Psychobiology examines disturbances in biological regulatory processes following separation from a close social partner and its impact on psychological and physical health (Hofer, 1987, 1994, 1996). Evolutionary psychology considers evolved psychological mechanisms underlying the functional significance of specific behaviors and behavioral processes (Bailey, 1997; Buss, 1999).

\section{Psychobiological Perspective on Bereavement}

Central to a psychobiological perspective on bereavement is the concept that the preexisting relationship between sur- vivor and deceased serves a regulatory role in their biological systems. Removal of the regulator, as in the loss experience, may be associated with profound biological changes in bereaved individuals. It is suggested that:

...when one person becomes enormously important to another, unrelated events and interactions have relatively little impact; thus, the loss of this one source may actually constitute a massive deprivation of relevant environmental input. In addition, the social withdrawal and self-enforced inactivity of the bereaved may contribute to the sensory deficit and may intensify the symptoms (Hofer, 1984, p. 189).

Barkow (1989) has suggested that, as humans evolved as social beings, the capacity for forming mental representations of significant others also evolved. Such representations may serve a biological regulatory function, as well as facilitate temporary separations. Both representational and actual interactions may be affected by permanent loss (Hofer, 1996). Individual differences in the severity of biological disturbance might vary with the degree of genetic relatedness to the deceased, a finding anticipated by an evolutionary perspective.

\section{Evolutionary Perspective on Bereavement}

An evolutionary perspective directs attention to the origins, functions and adaptive significance of human behaviors (Buss, 1999; Segal, 1993, 1997). Hamilton (1964a, b) asserted that natural selection favors alleles predisposing individuals to behave in ways that favor transmission of those alleles. As such, behaviors augmenting the reproductive fitness of close relatives, even at cost to the benefactor, will facilitate representation of shared genes, a concept termed "inclusive fitness". An evolutionary perspective has offered novel intepretations of child abuse (Daly \& Wilson, 1994), mate selection (Buss, 1989), physical attractiveness (Mealey \& Townsend, 1999) and other behaviors.

Address for correspondence: Nancy L. Segal, Department of Psychology, California State University, Fullerton, California 92834,USA.Email: nsegal@fullerton.edu 
Evolutionary reasoning suggests that grief response following loss should vary as a function of genetic relatedness between survivor and deceased, associated with diminished opportunities for transmission of genes into future generations. Consistent with this view is that most scale scores on the Grief Experience Inventory were higher for bereaved parents than for bereaved children or spouses (Sanders, 1989), and higher for parents who lost young adult children than for parents who lost infants (Rubin, 1989-1990). Neither study was conducted with reference to evolutionary considerations; in fact, many psychologists are unaware of the evolutionary implications of their work (Scarr, 1995). A key point is that evolutionary theorizing does not deny or diminish other theoretical perspectives; rather, it offers another interpretive framework for evaluating behavioral observations.

\section{Family and Twin Studies of Bereavement}

Littlefield and Rushton (1986) reported higher levels of parental grief for deceased children perceived as resembling their own family members, relative to their spouse's family members. Crawford et al. (1989) reported a higher correlation between grief intensity and reproductive value than between grief intensity and age of the deceased individual. Age of the decedent at loss (if past early adulthood) would, however, be expected to negatively correlate with grief because loss of reproductively able individuals would reduce the potential inclusive fitness of close relatives.

Twin research has previously found higher levels of both anticipated and genuine grief among MZ and samesex twins than DZ and opposite sex twins (Segal, 1999 and references therein; Mowrer, 1954; Woodward, 1998), supporting an association between degree of genetic relatedness and bereavement response. In addition, grief intensity ratings for deceased twin siblings ( $\mathrm{MZ}$ and $\mathrm{DZ}$ combined) significantly exceeded twins' ratings for deceased mothers, fathers, non-twin siblings, grandmothers, grandfathers, aunts, uncles and cousins. These differences increased when only MZ twins were selected. Bereaved MZ twins also showed more persistent levels of grief over time than bereaved DZ twins (Segal \& Ream, 1998). It is further revealing that non-twin individuals indicated greater perceptions of close relatedness to fictional identical twins than to other kin, both actual and fictional (Burnstein et al., 1994).

A genetic model would predict similar levels of grief following the loss of a of a DZ twin and full sibling, both of whom share an average of $50 \%$ of their genes with the survivor. Such data are not currently available in the literature. However, the California Twin Loss study included 24 DZ twins who had lost sisters and 49 DZ twins who had lost brothers, as well as twins. These DZ twins' grief intensity ratings were significantly higher for their deceased co-twins than for their deceased non-twin siblings (Segal, unpublished). This could be partly explained by the greater sharing of social experiences among DZ twins, due to their common age.

$\mathrm{MZ}$ twin mothers and fathers share the same genetic relationship (50\%) with their co-twins' children (nieces and nephews) as with their own children. Investing in nieces and nephews, therefore, offers the same genetic advantage as investing in one's own offspring. In "evolutionary currency," the loss of an $M Z$ co-twin represents a reduction of expected reproductive potential (Segal, 1993). DZ twin mothers and fathers share an average of $25 \%$ of their genes with their co-twins' children. Investment in these nieces and nephews, and grief at their loss, would be expected to be more variable.

\section{Sex-related Differences in Bereavement Response}

The psychological literature includes many examples of more frequent and severe emotional and physical responses among bereaved females than males (Segal, 1998; Shucter \& Zisook, 1993; Sprang et al., 1992-93; Stroebe \& Stroebe, 1987). In contrast, males generally express fewer and less severe bereavement-related behaviors. For example, findings of lower grief intensity ratings for deceased children by fathers than mothers, by maternal grandfathers and paternal grandmothers (combined) than maternal grandmothers, and by fathers' siblings than mothers' siblings have been reported (Littlefield \& Rushton, 1986). This finding may be partly linked to paternity uncertainty in males; see Buss (1999). The greater personal significance of kinship among females than among males has also been found (Salmon \& Daly, 1996). This suggests that females have been more reproductively successful by receiving assistance from, and investing in, close kin. In contrast, males might have been more reproductively successful by acquiring additional mates (see Buss, 1999, and references therein). Given that this pattern has not been observed crossculturally, interpretation of this finding awaits further study.

Males also express less death anxiety than females, possibly reflecting the cultural expectation that males display fortitude during times of stress (Lonneto \& Templer, 1986). It is, however, conceivable that observed sex differences may be less in the quality of reactions than in their expression. A noteworthy exception to the above is that widowers are at greater risk for mortality than widows (Stroebe \& Stroebe, 1993). Risk is especially heightened when spouses' loss occurs suddenly. The authors note, however, that inconsistencies in the relevant longitudinal studies urge additional, multivariate approaches in the future.

\section{Health of Deceased}

Evolutionary theorizing suggests that the unexpected loss of a young, healthy relative should be especially devastating, as it would eliminate a potential source of genetic representation. Littlefield and Rushton (1986) did, in fact, find that parents grieve more intensely for deceased healthy children than for deceased unhealthy children.

Sudden, as well as stigmatized loss (i.e., loss due to accident, suicide or murder), has been associated with increased persistent emotional stress and physiological change in survivors, relative to anticipated loss (Epstein, 1993; Martin \& Dean, 1993; Sanders, 1993). Sudden loss does not provide individuals with adequate opportunities to prepare for this event. In contrast, anticipated loss (e.g., loss due to chronic illness) has been associated with fewer somatic symptoms in survivors than sudden loss because of opportunities for relationship resolution (Bugen, 1977). 


\section{The Present Study: Research Issues and Hypotheses}

Genetic relatedness has rarely been considered among the features of previous social relationships affecting the nature and level of grief following loss. Genetic relatedness, per se, is not proposed as the critical variable underlying individual differences in bereavement response. Instead, genetic relatedness is considered a proxy for mechanisms associated with kin recognition and with the emotional and cognitive processes facilitating social bonding among relatives.

Specific predictions in the present study corresponded to tests included in bereavement models based on psychobiological and evolutionary perspectives.

\section{Psychobiological Predictions}

- Social Closeness: Increased social closeness with the cotwin will be associated with: 1. increased grief; 2 . increased somatic symptoms; and 3. greater impairment in self-perceived coping, holding constant the effects of zygosity, age at loss, sex, health of the deceased co-twin and loss interval (time since loss).

- Grief: Increased grief will be associated with: 4. increased somatic symptoms; and 5. greater impairment in coping, holding constant the effects of zygosity, twins' social closeness, age at loss, sex, health status of the deceased co-twin and loss interval.

- Somatic Symptoms: Increased somatic symptoms will be associated with: 6. greater impairment in coping, holding constant the effects of zygosity, twins' social closeness, age at loss, sex, health status of the deceased co-twin and loss interval.

\section{Evolutionary Predictions}

- Zygosity: Relative to DZ twins, MZ twins will show: 7. increased social closeness; 8. increased grief; 9. increased somatic symptoms; and 10. greater impairment in coping, holding constant the effects of age at loss, sex, health status of the deceased co-twin and loss interval. Hypotheses 8, 9 and 10 also hold constant the effect of social closeness.

- Age at Loss: Younger age at loss will be associated with: 11. increased grief; 12 . increased somatic symptoms; and 13. greater impairment in coping, holding constant the effects of zygosity, twins' social closeness, sex, health of the deceased co-twin and loss interval.

- Sex: Relative to males, bereaved females will report: 14 . increased grief; 15 . increased somatic symptoms; and 16. greater impairment in coping, holding constant the effects of zygosity, closeness, age at loss, health status of the deceased co-twin and time since loss.

- Health of Deceased Co-twin: Relative to the loss of an unhealthy co-twin, the loss of a healthy co-twin will be associated with: 17. increased grief; 18. increased somatic symptoms; and 19. greater impairment in coping, holding constant the effects of zygosity, twins' social closeness, age at loss, sex and loss interval.

\section{$\overline{\text { Method }}$ \\ Background of the Study}

The California State University, Fullerton (CSUF) Twin Loss Study (formerly the Minnesota Twin Loss Study) began in 1983. Participants complete a comprehensive Twin Loss Survey (TLS), mostly by mail. Components of the TLS include a Grief Intensity Scale (GIS) to assess overall response to the loss of the co-twin and other relatives, the Grief Experience Inventory (GEI) to assess behaviors and symptoms during the grief process, and a Coping Scale to assess coping with daily responsibilities and activities. Further details about the study are provided in Segal et al. (1995) and Segal and Ream (1998).

\section{Participants}

Participants were identified through twins clubs, twin loss support groups, attorneys, members of the media, other twin studies and personal referrals. The participation rate of twins contacted through twin loss support groups was approximately $50 \%$. Only twins whose age at loss was minimally 15 years were used in the present analyses to insure recollection of the loss experience. Several bereaved twins were reared apart from birth and reunited as adults. Complete or nearly complete data sets were available for 397 twins.

When the study began, surviving twins $(n=245)$ completed a retrospective version of the GEI. They were asked to respond to items with specific reference to "the first month or two following the loss." Questions were presented in the past tense and rewritten to refer to the deceased co-twin. Approximately midway through the study, surviving twins $(n=152)$ completed a revised version of this inventory in which items reflected current or persistent bereavement responses. Here they were asked to refer more broadly to "the period of bereavement," and to endorse current thoughts and feelings. Items were presented in the original tense (mostly present) and, again, were rewritten to refer to the deceased co-twin. Note that twins in the two groups (retrospective and current) were independent. It was anticipated that MZ-DZ bereavement differences would be greater for twins in the current group. This was because the initial emotional impact of losing the twin might overwhelm twin group differences. More severe and persistent grief among $M Z$ than $D Z$ twins in the current group (both of whom would have had opportunities for support) would direct attention to genetic influences on bereavement response.

Psychobiological and evolutionary hypotheses were assessed with respect to both time frames. The benefits and shortcomings of retrospective and prospective quasi-experimental designs are well known (Ellis, 1994). Importantly, twins in the two groups did not differ in age at participation, age at loss or time from loss to participation in the study.

Twins in the present sample partially overlap with those included in studies by Segal and Bouchard (1993), Segal et al. (1995), and Segal and Ream (1998). Complete data were available for 198 twins in the retrospective group and for 130 twins in the current group; other twins were missing data for one or two variables. As described later in the Results section, analyses proceeded using a statistical 
technique which makes use of all available data; that is, individuals with incomplete data were not omitted from the study. Observed data patterns (seven patterns for both groups) are displayed in Table 1 . It can be seen, for example, that five people in the retrospective group had complete data for all study variables, with the exception of somatic symptoms and coping (pattern 4).

Descriptive characteristics of the twins are presented in Table 2. Zygosity was mostly assigned by the Nichols and Bilbro (1966) physical resemblance questionnaire that shows 93\% agreement with blood-typing results. (Scoring rules were slightly modified because information was available from only one co-twin.) The retrospective group included 200 surviving MZ twins and 45 surviving DZ twins, and the current group included 122 surviving $M Z$ twins and 30 surviving DZ twins. Only same-sex DZ twins were used for comparability with the MZ twin sample. The

\section{Table 1}

Patterns of Observed Responses

\begin{tabular}{|c|c|c|c|c|c|c|c|}
\hline \multirow[b]{2}{*}{ Variable } & \multicolumn{7}{|c|}{ Pattern } \\
\hline & 1 & 2 & 3 & 4 & 5 & 6 & 7 \\
\hline \multicolumn{8}{|l|}{ Retrospective Group } \\
\hline Closeness & $x$ & $x$ & $\mathrm{x}$ & $\mathrm{x}$ & $x$ & $x$ & $x$ \\
\hline Grief & $x$ & $x$ & $x$ & $x$ & $\bullet$ & $x$ & $\mathrm{x}$ \\
\hline Somatic & $x$ & $x$ & $\bullet$ & $\bullet$ & $x$ & $x$ & $\mathrm{x}$ \\
\hline Coping & $x$ & $\bullet$ & $x$ & $\bullet$ & $x$ & $x$ & $\bullet$ \\
\hline Zygosity & $x$ & $x$ & $x$ & $x$ & $x$ & $x$ & $\mathrm{x}$ \\
\hline Age at Loss & $\mathrm{x}$ & $x$ & $x$ & $x$ & $\mathrm{x}$ & $x$ & $x$ \\
\hline Sex & $x$ & $x$ & $x$ & $x$ & $x$ & $x$ & $\mathrm{x}$ \\
\hline Health Status & $x$ & $x$ & $x$ & $x$ & $x$ & $\bullet$ & $\bullet$ \\
\hline Loss Interval & $\mathrm{x}$ & $x$ & $x$ & $\mathrm{x}$ & $\mathrm{x}$ & $x$ & $x$ \\
\hline Total & 198 & 7 & 31 & 5 & 2 & 4 & 1 \\
\hline \multicolumn{8}{|l|}{ Current Group } \\
\hline Closeness & $x$ & $x$ & $x$ & $\mathrm{x}$ & $x$ & $x$ & $x$ \\
\hline Grief & $x$ & $x$ & $x$ & $x$ & $\bullet$ & $\bullet$ & $\bullet$ \\
\hline Somatic & $x$ & $x$ & $\bullet$ & $\bullet$ & $x$ & $x$ & $\bullet$ \\
\hline Coping & $x$ & $\bullet$ & $x$ & $\bullet$ & $x$ & $\bullet$ & $x$ \\
\hline Zygosity & $x$ & $x$ & $x$ & $\mathrm{x}$ & $x$ & $x$ & $x$ \\
\hline Age at Loss & $x$ & $x$ & $x$ & $x$ & $x$ & $\mathrm{x}$ & $\mathrm{x}$ \\
\hline Sex & $x$ & $x$ & $x$ & $x$ & $x$ & $x$ & $x$ \\
\hline Health Status & $x$ & $x$ & $x$ & $x$ & $x$ & $x$ & $\mathrm{x}$ \\
\hline Loss Interval & $x$ & $x$ & $x$ & $x$ & $\mathrm{x}$ & $x$ & $x$ \\
\hline Total & 130 & 7 & 9 & 3 & 1 & 1 & 1 \\
\hline
\end{tabular}

Note: ' $x$ ' indicates observed variable; ' $\bullet$ ' indicates missing variable sample contains an overrepresentation of $M Z$ twins (4:1 in both groups) and females (2:1 in the retrospective group and 5:1 in the current group). The typical ratio in volunteer twin studies is closer to 2:1 for both zygosity and sex (Lykken et al., 1990). The excess of MZ twins in the present study could reflect $M Z$ twins' greater investment in the twin relationship, relative to $\mathrm{DZ}$ twins. Reasons for the elevated proportion of females in the current group are less certain.

Approximately $50 \%$ of $\mathrm{MZ}$ twins in both groups were identified through twin loss support groups. This was the case for a slightly higher proportion of DZ twins in the retrospective group (62\%), and a slightly lower percentage of DZ twins in the current group (43\%). Cause of death for all participants was approximately distributed among illness $(57.2 \%)$, accidents $(28.2 \%)$, suicide $(10.1 \%)$, murder $(2.8 \%)$, advanced age $(0.3 \%)$ and other causes $(1.4 \%)$. These percentages were similar to those for both $\mathrm{MZ}$ and $\mathrm{DZ}$ twins in the retrospective and current groups.

\section{Materials}

Coping Scale. The Coping Scale, developed by Littlefield (unpublished), assesses perceived ability to cope with the needs of children, needs of spouse, relationship with family members, relationship with close friends, household chores, job performance, relationship with colleagues or classmates, and life in general. Twins rated coping abilities ( $1=$ extremely poor to 5 = extremely well) as experienced during the month or two before the twin died (Time 1), during the month or two after the twin died (Time 2), and at the time the questionnaire was completed (Time 3). Ratings at Time 1 and Time 2 were retrospective, while ratings at Time 3 were current. In the present study, Time 2 coping items were used for twins in the retrospective group and Time 3 coping items were used for twins in the current group; Time 1 items were not included. The time from loss to participation (loss interval) varied across participants. The range was 0 to 54 years, and did not differ between $\mathrm{MZ}$ and DZ twins in the retrospective or current groups. Scoring of items was reversed in the present analysis so higher scores reflected poorer coping.

Somatization Scale. The Somatization Scale is one of nine Bereavement scales comprising the Grief Experience Inventory (GEI; Sanders et al., 1985). It includes 20 true/false items associated with sleep disturbance, drug usage, physiological complaints, decreased physical strength and appetitive symptoms. According to the inventory

Table 2

Age, Age at Loss, Years Since Loss and Gender Composition for Bereaved MZ and Same-sex DZ Co-twins in Retrospective and Current Groups

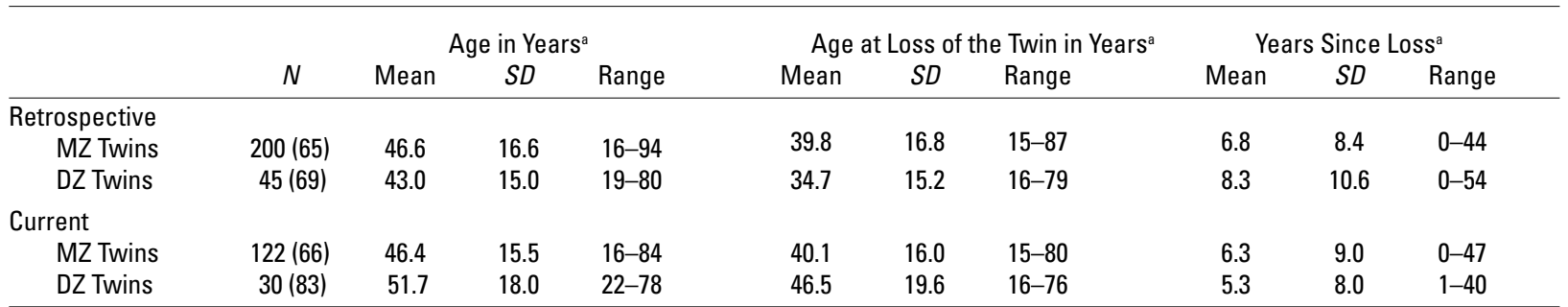

Note: ${ }^{a} \mathrm{MZ}$ vs DZ: $n s$

( ) = Per cent Female 
manual, the test-retest reliability using a college student sample and an interval of 9 weeks, was .87. A value of .55 was obtained using an early bereavement group, but with an 18-month interval.

In the present study, items were rephrased to reflect bereavement during the first month or two following the loss (retrospective group). Items were left in their original current time frame for the remaining twins (current group). The score on this scale was the sum of symptoms endorsed. ${ }^{1}$ In the present study, coefficient alpha was estimated to be .86 for the retrospective group and .85 for the current group.

Grief Intensity Scale (GIS). The GIS obtains ratings of grief $(1=$ no grief to 7 = total devastation; suicide point $)$ in response to the loss of the twin and other relatives and acquaintances, as experienced one to two months following the event (retrospective group) and currently (current group). The GIS was developed for a study of parental bereavement (Littlefield \& Rushton, 1986) and modified for the present twin study. Littlefield \& Rushton (1986) reported a mean reliability of .52 (.32 to .72), based on correlations between spouses' grief intensity ratings of their relatives. They also reported a validity coefficient of .52 , based on the correlations between respondents' self-ratings of grief and their total scores on Sanders's Grief Experience Inventory. Twins' GIS ratings (retrospective) showed correlations of .40-.58 with eight of the nine Bereavement scales on the GEI (Segal et al., 1995), and a correlation of .46 with the Life in General rating (Time 2) from the Coping Scale.

Social Closeness Rating. A social closeness scale (7 = much less close than casual friends to $1=$ much closer than any best friend) was used to evaluate the nature of twins' relations with each other. Participants selected the statement that was "most characteristic" of their social relationship. This item was presented similarly to twins in the retrospective and current groups so did not reflect a specific time frame closeness items were reverse scored in the analyses.

Health of Deceased Co-Twin. Co-twins whose deaths were due to protracted illnesses were considered unhealthy, while co-twins whose deaths were due to accidents, murder or suicide $^{2}$ were considered healthy. The health status of co- twins whose deaths were due to a terminal illness and occurred within seven days from the time that the survivor learned of the death prognosis were classified as healthy (Sanders, 1979-1980).

\section{Data Analysis}

Grouping variables were coded as follows: zygosity $(\mathrm{MZ}=$ $0 ; \mathrm{DZ}=1)$, sex $($ male $=0 ;$ female $=1)$, health of the deceased ( 0 = unhealthy; 1 = healthy $)$ and somatic symptoms $($ present $=1$; not present $=0)$. Somatization scores were not computed for individuals missing two or more of these scale items.

\section{Coping Scale}

Coping 1-2 months after the loss (Time 2) was assessed using data from twins responding to retrospectively worded items, and coping at the present time (Time 3) was assessed using data from twins responding to currently worded items. The frequency of valid scores for coping with needs of children, needs of spouse, job responsibilities and relationships with co-workers or classmates were lowest, relative to the other coping measures, because some twins were childless, unmarried and/or unemployed. These four measures were eliminated from further consideration.

Two coping scales (Time 2 and Time 3) were constructed by summing the remaining four items (coping with household chores, relationships with family members, relationships with close friends, and life in general). Cases which had valid scores for at least three of the four variables at each time period were retained (Time 2: $n=232$; Time 3: $n=141$ ). A new score for twins with one missing item was calculated on a case-by-case basis by averaging the three completed items and replacing the missing response with this value.

\section{Results}

Zero-order correlations (using pairwise deletion) among the relevant variables are presented separately for the retrospective and current groups in Tables $3 \mathrm{a}$ and $3 \mathrm{~b}$. Mean scores for $\mathrm{MZ}$ and $\mathrm{DZ}$ twins for grief, somatic symptoms and coping are shown in Table 4.

Separate path analyses for the retrospective and current groups were performed using LISREL version 8.5. Using

\section{Table 3a}

Zero-order Correlations Between Predictor and Outcome Measures for Retrospective Responses

\begin{tabular}{|c|c|c|c|c|c|c|c|c|}
\hline & GRIEF & SOMATIC & COPING & CLOSE & ZYG & SEX & AGELOSS & HEALTH \\
\hline SOMATIC & $.49 * *$ & & & & & & & \\
\hline COPING & $-.48^{* *}$ & $.47^{* *}$ & & & & & & \\
\hline CLOSE & $.23^{* *}$ & $.23^{* *}$ & -.02 & & & & & \\
\hline ZYG & $-.15^{*}$ & $-.21^{* *}$ & -.06 & $-.30^{* *}$ & & & & \\
\hline SEX & .12 & $.21^{* *}$ & $.14^{*}$ & -.04 & .04 & & & \\
\hline AGELOSS & $-.22^{* *}$ & $-.24^{* *}$ & $-.28^{* *}$ & -.02 & -.12 & .12 & & \\
\hline HEALTH & $.24^{* *}$ & $.19^{* *}$ & $.20^{* *}$ & .04 & -.07 & $-.15^{*}$ & $-.36^{* *}$ & \\
\hline LOSSINT & -.09 & $-.29 * *$ & -.01 & .00 & .07 & $-.16^{*}$ & $-.30^{* *}$ & .08 \\
\hline
\end{tabular}

Note: MZ AND DZ twins combined, pairwise deletion, $n$ 's: 207-245. GRIEF: grief intensity; SOMATIC: somatic symptoms; COPING: Coping; CLOSE: closeness; ZYG: Zygosity; SEX: sex of survivor; AGELOSS: age at loss; HEALTH: health of deceased; LOSSINT: loss interval (time since loss). ${ }^{*} p<.05$ (2-tailed); ${ }^{* *} p<.01(2$-tailed) 
Table 3b

Zero-order Correlations Between Predictor and Outcome Measures for Current Responses

\begin{tabular}{|c|c|c|c|c|c|c|c|c|}
\hline & GRIEF & SOMATIC & COPING & CLOSE & ZYG & SEX & AGELOSS & HEALTH \\
\hline SOMATIC & $.33^{* *}$ & & & & & & & \\
\hline COPING & $.38^{* *}$ & $.32^{* *}$ & & & & & & \\
\hline CLOSE & $.30^{* *}$ & .11 & .03 & & & & & \\
\hline ZYG & $-.22^{* *}$ & -.02 & $-.17^{*}$ & $-.19^{*}$ & & & & \\
\hline SEX & $.16^{*}$ & $.19^{*}$ & .02 & $-.17^{*}$ & .15 & & & \\
\hline AGELOSS & -.04 & $-.19^{*}$ & -.07 & .11 & .15 & .02 & & \\
\hline HEALTH & .02 & $.24^{* *}$ & $.20^{*}$ & .09 & .03 & -.14 & $-.33^{* *}$ & \\
\hline LOSSINT & -.12 & -.11 & $-.25^{* *}$ & -.09 & -.05 & -.10 & $-.35^{* *}$ & .10 \\
\hline
\end{tabular}

Note: MZ AND DZ twins combined, pairwise deletion, n's: 131 - 152. GRIEF: grief intensity; SOMATIC: somatic symptoms;COPING: Coping; CLOSE: closeness; ZYG: Zygosity; SEX: sex of survivor; AGELOSS: age at loss; HEALTH: health of deceased; LOSSINT: loss interval (time since loss)

${ }^{*} p<.05$ (2-tailed); ${ }^{* *} p<.01$ (2-tailed)

Table 4

Mean Scores and Standard Errors for MZ and DZ Twins for Grief, Somatic Symptoms and Coping

\begin{tabular}{lcccc}
\hline & \multicolumn{2}{c}{ Retrospective } & \multicolumn{2}{c}{ Current } \\
& $\mathrm{MZ}$ & $\mathrm{DZ}$ & $\mathrm{MZ}$ & $\mathrm{DZ}$ \\
\hline GRIEF & $5.93(.082)$ & $5.47(.205)$ & $4.73(.136)$ & $3.90(.245)$ \\
& $n=198$ & $n=45$ & $n=120$ & $n=29$ \\
SOMATIC & $8.71(.363)$ & $6.14(.684)$ & $6.62(.430)$ & $6.39(.890)$ \\
& $n=172$ & $n=37$ & $n=111$ & $n=28$ \\
COPING & $3.36(.064)$ & $3.21(.182)$ & $3.59(.076)$ & $3.94(.145)$ \\
& $n=191$ & $n=41$ & $n=114$ & $n=26$ \\
\hline
\end{tabular}

full information maximum likelihood, missing data are handled so that all individual data records can be included in the analysis regardless of the observed data pattern (see du Toit $\&$ du Toit, 2001). Missing data are assumed to be missing at random in the sense that missing data patterns are independent of the missing data. This approach, which is gaining attention, differs from common approaches that require complete data as they rely on sufficient statistics, such as a mean vector and covariance matrix. When data are incomplete and the assumptions concerning the missing data are met, this approach is often preferred over the commonly applied available-case techniques which can result in biased estimates. Even when the assumptions concerning missing data are not strictly met, this approach often yields better estimates (see Muthen et al., 1987). The goals of the present analyses were to evaluate path coefficients reflecting hypothesized associations; remaining path coefficients were not tested for statistical significance.

Due to the small sample sizes, tests were limited to those listed above; tests of possible interaction effects among independent variables were not included. Each analysis consisted of multiple paths of which only the nineteen reflecting hypothesized associations were evaluated. Using an overall significance level of .20, a Bonferroni multiple comparisons procedure was used to test the 19 hypotheses. Each test was evaluated at $.20 / 19=.01$. Using a significance level of .01 and one-sided tests, the critical value for evaluating individual coefficients is $t=2.326$. This step insures that the maximum Type I error rate will not exceed .20. This is a more conservative method of testing individual path coefficients that are typically tested at a nominal level of, for example, .05. An overall significance level of .20 was used to help improve the power of individual tests (Stevens, 1996).

\section{Evaluation of Retrospective Responses}

The model reflecting retrospective responses is shown in Figure 1. Path coefficients are standardized. Solid lines represent hypothesized associations, while dashed lines represent untested associations. Maximum likelihood estimates with standard errors, $t$-ratios and standardized coefficients are listed in Table 5.

Psychobiological Hypotheses. Path coefficients were large relative to the estimated standard errors, supporting four of the six psychobiological hypotheses (1, 4, 5 and 6): effects of Closeness on Grief, Grief on Somatic Symptoms, and Grief and Somatic Symptoms on Coping. The effects of twins' Closeness on Somatic Symptoms and on Coping difficulties were not statistically significant.

Evolutionary Hypotheses. Seven of the 13 retrospective evolutionary hypotheses were supported $(7,9,11,12,14$, 15 and 17): effects of Zygosity on Closeness and Somatic Symptoms, Age at Loss and Sex on Somatic Symptoms, and Age, Sex and Health of Deceased on Grief. The effects of Zygosity on Grief, Zygosity, Age at Loss, Sex and Health of Deceased on Coping, and Health of Deceased on Somatic Symptoms were not statistically significant.

As shown in Figure 1, the relationship between Zygosity and Grief is mediated by Social Closeness. To test for a mediating relationship we followed steps outlined in Baron and Kenny (1986). First, we computed the direct effect of Zygosity on Grief, dropping the paths from Zygosity to Closeness and from Closeness to Grief and holding constant the effects of other variables. The path coefficient was statistically significant $(-.504$ with standard error $.183, t=-2.74)$, suggesting a possible causal influence of genetic relatedness on grief intensity. Next, we examined the indirect effect of Zygosity on Grief, computed as the product of path coefficients from Zygosity to Closeness and Closeness to Grief: $-.596 \times .340=-2.03$ with a standard error of $.072, t=-2.82$. The direct effect of Zygosity on Grief, taking into account the mediating effect of 


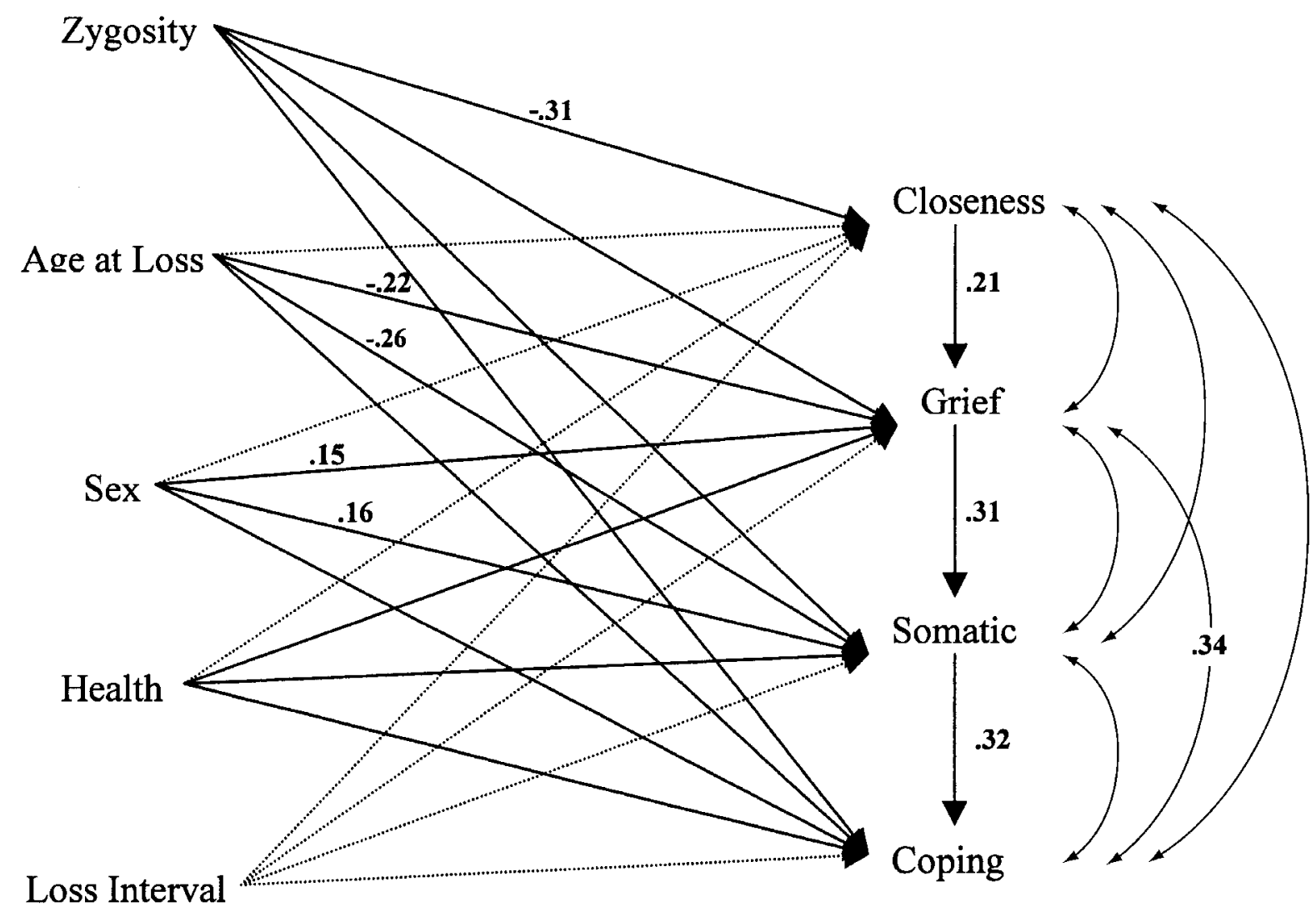

\section{Figure 1}

Model depicting associations among bereavement variables (retrospective group). Solid lines reflect hypothesized associations, dashed lines reflect untested associations.

Closeness, dropped from -.504 to -.290 . This represents a decrease of $42 \%$. However, the direct effect of Zygosity on Grief in the mediated model was not statistically significant, suggesting that the relationship between Zygosity and Grief may be fully mediated by Closeness, adjusting for effects of age at loss, sex, health status of the deceased and time since loss. Specifically, MZ twins showed greater social closeness which, in turn, lead to somewhat elevated grief.

\section{Evaluation of Current Responses.}

A model reflecting current bereavement responses is shown in Figure 2. Path coefficients are standardized. Again, solid lines represent hypothesized associations, while dashed lines represent untested associations. Maximum likelihood estimates with standard errors and standardized coefficients are listed in Table 5.

Psychobiological Hypotheses. Four of the six current psychobiological hypotheses (1, 4, 5 and 6) were supported: effects of Closeness on Grief, Grief on Somatic Symptoms and Coping, and Somatic Symptoms on Coping. Hypotheses concerning the effects of Closeness on Somatic Symptoms and Coping, and the effects of Closeness, Grief and Somatic Symptoms on Coping were not supported. These findings mirror those reported for the retrospective twin group.

Evolutionary Hypotheses. Only five of the 13 evolutionary predictions generated by current data $(7,8,15,18$ and 19) were supported. As expected, $\mathrm{MZ}$ twins reported greater social closeness and grief intensity than did DZ twins. In addition, a higher number of somatic symptoms were reported by females than males, and by twins losing a healthy co-twin than an unhealthy co-twin. Twins losing a healthy co-twin reported greater difficulty in coping. We also tested the mediational relationship between Zygosity and Grief for the current group. First, we tested the direct effect of Zygosity on Grief, dropping the paths from Zygosity to Closeness and from Closeness to Grief, as shown in Figure 2. The path coefficient was statistically significant (-.988 with standard error $.291, t=-3.393)$, suggesting a causal influence of genetic relatedness on grief intensity. Next, we tested the indirect effect of Zygosity on Grief when mediated by Closeness. This was computed as the product of path coefficients from Zygosity to Closeness and from Closeness to Grief-. $432 \times .476=-2.06$ with a standard error of .103 , 
Table 5

Maximum Likelihood Estimates, Standard Errors and Standardized Coefficients for Psychobiological and Evolutionary Model Paths, for Retrospective and Current Bereavement Responses

\begin{tabular}{|c|c|c|c|c|}
\hline Path & MLE & $(S E)$ & Standardized Coefficient & $t$ \\
\hline \multicolumn{5}{|l|}{ Psychobiological: Retrospective } \\
\hline 1. Direct effect of CLOSE on GRIEF & .34 & (.10) & .21 & -3.40 \\
\hline 2. Direct effect of CLOSE on SOM & .71 & (.38) & -.11 & -1.88 \\
\hline 3. Direct effect of CLOSE on COPING & -.17 & $(.07)$ & -.13 & -2.23 \\
\hline 4. Direct effect of GRIEF on SOM & 1.23 & (.24) & .31 & 5.09 \\
\hline 5. Direct effect of GRIEF on COPING & .27 & $(.05)$ & .34 & -5.31 \\
\hline 6. Direct effect of SOM on COPING & .06 & $(.01)$ & .32 & -4.47 \\
\hline \multicolumn{5}{|l|}{ Evolutionary: Retrospective } \\
\hline 7. Direct effect of ZYG on CLOSE & -.60 & (.12) & -.31 & 5.03 \\
\hline 8. Direct effect of ZYG on GRIEF & -.29 & (.19) & -.09 & -1.49 \\
\hline 9. Direct effect of ZYG on SOMATIC & -1.59 & (.72) & -.13 & -2.20 \\
\hline 10. Direct effect of ZYG on COPING & .05 & $(.14)$ & -.02 & 0.36 \\
\hline 11. Direct effect of AGELOSS on GRIEF & -.02 & $(.01)$ & -.22 & -3.31 \\
\hline 12. Direct effect of AGELOSS on SOM & -.08 & $(.02)$ & -.26 & -4.12 \\
\hline 13. Direct effect of AGELOSS on COPING & .01 & $(.00)$ & -.12 & 1.86 \\
\hline 14. Direct effect of SEX on GRIEF & .39 & (.15) & .15 & 2.57 \\
\hline 15. Direct effect of SEX on SOM & 1.53 & (.57) & .16 & 2.70 \\
\hline 16. Direct effect of SEX on COPING & -.15 & $(.11)$ & -.07 & -1.30 \\
\hline 17. Direct effect of HEALTH on GRIEF & .50 & (.15) & .21 & 1.00 \\
\hline 18. Direct effect of HEALTH on SOM & .43 & (.58) & .05 & 0.74 \\
\hline 19. Direct effect of HEALTH on COPING & -.02 & $(.11)$ & -.01 & -0.13 \\
\hline \multicolumn{5}{|l|}{ Psychobiological: Current } \\
\hline 1. Direct effect of CLOSE on GRIEF & .48 & (.13) & .28 & -3.58 \\
\hline 2. Direct effect of CLOSE on SOM & .05 & (.43) & .01 & -0.12 \\
\hline 3. Direct effect of CLOSE on COPING & -.04 & $(.07)$ & -.04 & -0.55 \\
\hline 4. Direct effect of GRIEF on SOM & .85 & (.26) & .28 & 3.30 \\
\hline 5. Direct effect of GRIEF on COPING & .15 & (.05) & .28 & -3.40 \\
\hline 6. Direct effect of SOM on COPING & .03 & $(.02)$ & .16 & -1.92 \\
\hline \multicolumn{5}{|l|}{ Evolutionary: Current } \\
\hline 7. Direct effect of ZYG on CLOSE & -.43 & (.18) & -.19 & 2.39 \\
\hline 8. Direct effect of ZYG on GRIEF & -.81 & $(.30)$ & -.21 & -2.72 \\
\hline 9. Direct effect of ZYG on SOMATIC & .43 & (.94) & .04 & 0.45 \\
\hline 10.Direct effect of ZYG on COPING & -.25 & $(.16)$ & -.13 & 1.61 \\
\hline 11. Direct effect of AGELOSS on GRIEF & -.00 & $(.01)$ & -.01 & -0.10 \\
\hline 12. Direct effect of AGELOSS on SOM & -.04 & $(.02)$ & -.14 & -1.54 \\
\hline 13. Direct effect of AGELOSS on COPING & -.00 & $(.00)$ & -.06 & 0.67 \\
\hline 14. Direct effect of SEX on GRIEF & .42 & $(.26)$ & .13 & 1.63 \\
\hline 15. Direct effect of SEX on SOM & 1.40 & $(.60)$ & .14 & 1.75 \\
\hline 16. Direct effect of SEX on COPING & -.05 & $(.14)$ & -.03 & 0.36 \\
\hline 17. Direct effect of HEALTH on GRIEF & .30 & $(.25)$ & .10 & 1.20 \\
\hline 18. Direct effect of HEALTH on SOM & 1.98 & (.79) & .21 & 2.52 \\
\hline 19. Direct effect of HEALTH on COPING & .32 & (.14) & .19 & -2.37 \\
\hline
\end{tabular}

Note: Bold text indicates statistically significant coefficients at the .05 level, one-tailed test.

$t=1.99$. The direct effect of Zygosity on Grief, taking into account the mediating effect of Closeness, dropped from -.99 to -.81 , or by $18 \%$. The test of the indirect path from Zygosity to Grief, mediated by Closeness, was not statistically significant. These results suggest that the relationship between Zygosity and Grief may not be mediated by Closeness, adjusting for effects of age at loss, sex, health status of the deceased and time since loss. However, the direct effect of Zygosity on Grief for twins in the current group is statistically significant, suggesting a direct effect between genetic relatedness and grief intensity.

\section{Discussion}

Retrospective Responses

Psychobiological Hypotheses. Four of the six retrospective psychobiological predictions were supported. These findings are consistent with Hofer's $(1984,1996)$ psychobiological view that social relationships function to preserve critical biological functions, and that loss of those relationships is associated with disruption of those functions. Twins' social closeness showed a positive association with grief intensity which, in turn, affected somatic symptoms and coping efficacy in predicted directions. In addition, increased somatic symptoms lead to increased coping difficulties. Refinement of twins' social-interactional qualities into specific behavioral dimensions (e.g., trust and understanding) may further differentiate between bereaved twin groups, and among other bereaved relatives. Additional analyses of specific health-related characteristics should also improve a psychobiological model. For example, assessment of physical health prior to bereavement would enable estimation of the contribution of twin loss to changes in physical health. 


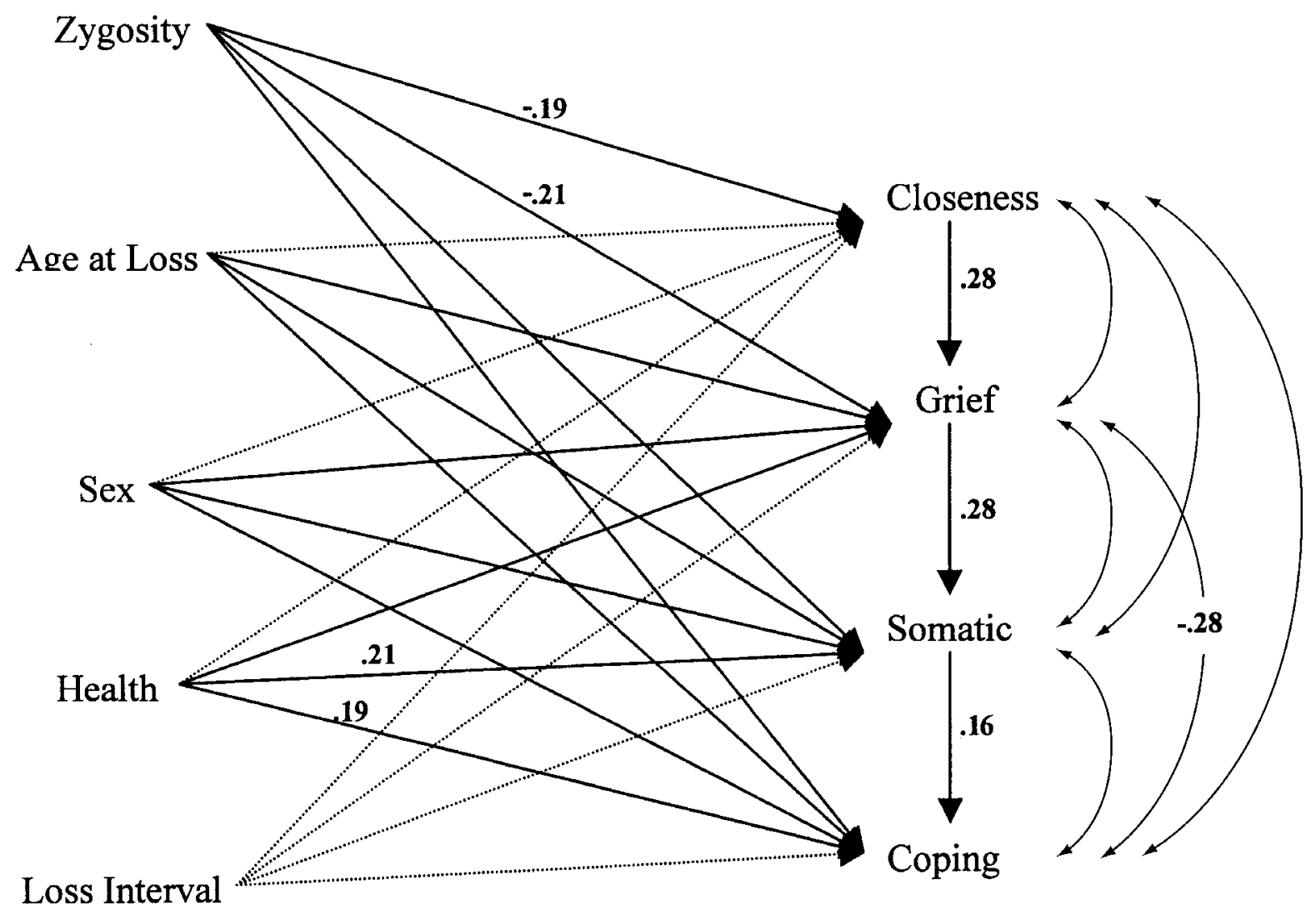

Figure 2

Model depicting associations among bereavement variables (current group). Solid lines reflect hypothesized associations, dashed lines reflect untested associations.

Evolutionary Hypotheses. Seven of the 13 retrospective evolutionary predictions were supported. Consistent with hypotheses 7 and 9, increased genetic commonality was significantly associated with increased social closeness and increased somatic symptoms. The direct association between zygosity and grief was not statistically significant under the condition that other variables, including social closeness, were held constant. The direct effect of zygosity on grief was then reexamined by dropping paths from zygosity to closeness and closeness to grief. This procedure suggests that the relationship between genetic commonality and grief intensity may be mediated by social closeness. This could partly explain the greater cooperation and affiliation observed between MZ than DZ co-twins (Segal, 2000). Consistent findings come from a recent non-twin study that identified emotional closeness as partially mediating the effect of genetic relatedness on willingness to perform altruistic acts (Korchmaros \& Kenny, 2001).

Younger age at loss was associated with increased grief and somatic symptoms, supporting the view that reproductively able individuals should be grieved for more intensely than reproductively less able individuals. This finding is generally consistent with that of Crawford et al. (1989) who found that the reproductive value of the deceased showed a stronger association with grief than his or her age. Being female was associated with increased grief and somatic symptoms, consistent with previous findings. Sex differences in bereavement response are quite complex (Sprang et al., 1992-3) and may vary with participant characteristics, such as past experience with loss and use of social support. As expected, loss of a healthy co-twin was associated with increased grief, although loss of a healthy co-twin was not associated with greater somatic symptoms or coping difficulties among survivors than loss of an unhealthy twin. It may be that global designation of deceased co-twins as healthy or unhealthy did not fully capture their specific health status.

\section{Current Responses.}

Psychobiological Hypotheses. Twins' social closeness was associated with current grief, and current grief was associated with current somatic symptoms and coping. Twins' social closeness was not associated with current somatic symptoms or coping. This finding was somewhat surprising for the current (and retrospective) groups. Again, attention to 
more specific interactional and health characteristics may refine this result.

Evolutionary Hypotheses. Increased genetic relatedness was significantly associated with increased social closeness, a finding consistent with that found for the retrospective group. The effect of zygosity on current grief implicates correlates of genetic relatedness as factors in the bereavement process. It is worth noting that the direct effect of zygosity on grief in the mediated model was statistically significant for the current group, but not for the retrospective group. Consideration of measures included in this study did not suggest any definitive explanations. As indicated, previous twin studies of bereavement have shown significantly increased grief and other bereavement-related behaviors among MZ than DZ twins. Meaningful resolution of this difference may be facilitated with reference to Segal \& Ream's (1998) finding that grief intensity ratings remained higher over time for $\mathrm{MZ}$ than $\mathrm{DZ}$ twins, controlling for initial level of grief and age at loss. In fact, as noted in Table 4, MZ-DZ differences in grief were larger for the current group than the retrospective group, and DZ twins showed greater decrease in scores (retrospective vs current) than $M Z$ twins. It is possible that the initial trauma of losing a twin dampens $\mathrm{MZ}-\mathrm{DZ}$ differences somewhat, so that (in the current group) MZ twins' higher overall grief is a more genuine reflection of a twin group difference in this measure.

The failure of some retrospective findings to remain significant in the current time frame is not surprising, given the passage of time since loss. It is, however, unclear why the effects of sex and health of the deceased co-twin on somatic symptoms and health of the deceased co-twin on coping remained statistically significant, while other effects did not.

\section{Mechanisms Associated with Social Closeness and Bereavement}

The present findings warrant consideration of mechanisms enabling discrimination within kinship categories ( $M Z$ vs DZ twinship), resulting in group differences in the outcome measures. Congruence (albeit, imperfect) between genotype and phenotype raises the possibility of evolved psychological mechanisms associated with attraction between related individuals who perceive similarities between themselves (Freedman, 1979; also see Trivers, 1985). Siblings share, on average, $50 \%$ of their genes, but some DZ co-twins (and some ordinary siblings) vary in degree of genetic overlap for selected traits (Loehlin, 1992). The degree of phenotypic similarity between relatives may, thus, offer a useful (albeit, approximate) index of genetic relatedness. Individuals perceiving increased similarities may experience greater social attraction and, consequently, more devastating reactions following loss. The present study suggested social closeness as a proximate mechanism underlying genetic relatedness and social behavior in the retrospective group, but other mechanisms remain to be identified. The absence of a mediating effect of Closeness in the relationship between Zygosity and Grief in the current group also warrants resolution.

MZ twinning is believed to occur randomly. Furthermore, it is a relatively rare event, occurring in approximately $1 / 250$ births worldwide. A special mechanism for responding to a genetically identical individual is not proposed; instead, increased grief following the loss of an $\mathrm{MZ}$ co-twin presumably reflects extension of the general principles described above. Additional discussion of these issues is presented in Segal $(1993,1997,2000)$.

\section{The Twin Sample}

It is possible that the participating twins comprised a somewhat unrepresentative portion of the bereaved twin population. This difficulty may apply more specifically to surviving DZ twins and males than to surviving $\mathrm{MZ}$ twins and females who were overrepresented among the respondents. DZ twins and males who were motivated to participate may have been especially bereaved (Segal, 2000). Access to a more representative sample of these particular twins would, therefore, most likely yield stronger associations among some of the variables (e.g., zygosity with retrospective grief). Recent evidence of a higher $M Z$ twinning rate and decline in the DZ twinning rate, based on data collected in Minnesota between 1971 and 1984, suggests that increased $\mathrm{MZ}$ twin representation in volunteer studies does not necessarily imply ascertainment bias (Hur et al., 1995); however, many twins in the study were born prior to that period. The greater susceptibility of males than females to early mortality could partly explain male twins' underrepresentation studies of loss (McGue et al., 1993). However, age at loss for surviving male twins in the present study was just slightly younger than that for females. More importantly, perhaps, male underrepresentation may reflect the expectation that males refrain from outward expressions of grief. Despite possible sampling issues, the pattern of findings which emerged is encouraging.

\section{Theoretical Issues}

Evolutionary interpretations of human behavioral variation have received warmer reception in recent years, yet resistance by many psychologists lingers (Mealey, 2000). It might be argued, for example, that findings from the present study were predictable from a twin study of social relationships. How then does the present psychobiological and evolutionary-based twin study enhance understanding of bereavement and concepts of kin selection and altruism, over and beyond what studies of social relatedness can contribute?

The present analysis demonstrated that relative genetic commonality was associated with level of social closeness and grief. The fact that proximate explanations (e.g., quality of the social relationship) may be consistent with differential bereavement response (Archer, 1988) does not detract from their interpretation within an evolutionary framework (Littlefield \& Rushton, 1989); rather, evolutionary interpretations may offer a "deeper and more generalized understanding of the phenomena” (p. 626). Evolutionary psychology can examine, and possibly explain, behaviors that would not be anticipated by a proximal approach. For example, evolutionary theory predicts that loss of a recently found $\mathrm{MZ}$ co-twin reared apart should be more devastating than the loss of an adoptive sibling. Consistent with the latter expectation are preliminary data showing that reunited $\mathrm{MZ}$ and $\mathrm{DZ}$ twins 
experience greater familiarity and expectations of social closeness with their co-twin, relative to the non-biological siblings with whom they were reared (Segal, 2000).

Significant associations between zygosity, closeness and bereavement-related behaviors may enrich more frequently invoked psychosocial explanations of grief and mourning. It may be asserted, for example, that individuals may grieve more intensely for close relatives than for more distant relatives because of more frequent association and interdependence. However, shared genes may drive the social relationship, rather than the other way around, so these behaviors may be the proximal or immediate correlates of social processes that evolve between close relatives (Segal, 1997).

Archer (1988, 1992, 1999) has questioned whether grieving represents adaptive behavior, given its association with physical and emotional stress. He has suggested that grief may be more appropriately viewed as a by-product of a characteristic that does enhance fitness (e.g., investment in a close personal relationship). It is, however, conceivable that stressful behaviors associated with separation are adaptive in some contexts, as they would promote reunion with significant others who are absent (Hofer, 1994; Littlefield \& Rushton, 1989). Nesse (1994) reminds us that emotions correspond to specific situations and may serve multiple functions. He suggests that unfavorable conditions may "induce low mood, which communicates the need for aid and submissive social withdrawal, and motivates conserving resources and considering other possible strategies or goals" (Nesse, 1991). The capacity for sadness may have, therefore, evolved to check the occurrence of additional losses (Nesse \& Williams, 1994). These themes are reiterated in Plutchik's (2001) evolutionary analysis of human emotions. He notes, for example, that crying and grieving following loss of a parent bring support and assistance from social group members. Grief associated with bereavement, while linked to some debilitating physical and/or psychological effects, may also serve useful functions.

Comparative studies of bereavement in reunited biological relatives, intact biological kinships and adoptive relationships would be revealing. Organizing pairs according to personality similarity and physical resemblance might help identify mechanisms associated with individual differences in social relatedness in general, and bereavement response in particular. An additional informative group of survivors would include biological relatives who did not enjoy harmonious relations with the deceased; these kinships would test Chagnon \& Bugos's (1979) assertion that crisis events best reveal affiliative tendencies. Personality characteristics of participants and life crises coincident with, or preceeding, the loss of a close relative can also influence bereavement processes and outcomes (Sanders, 1989). Prospective longitudinal studies could track events associated with grieving among different groups of relatives.

In summary, twin and adoption methods offer powerful tools for investigating genetic and environmental influences on behavioral variation. Their potential contribution to psychobiological and evolutionary-based studies has not been realized (Scarr, 1995, Segal, 2000).

\section{Footnotes}

1 The GEI manual recommends $t$ score transformation of individual scores prior to statistical analysis. ( $t$ score equivalents for each scale are provided with the test materials.) This procedure was not performed given the modification of items for purposes of the present study.

2 There is controversy among bereavement researchers over whether suicide represents an anticipated or sudden event (Sanders, 1989; Reed \& Greenwald, 1991). Suicidal loss was classified as sudden in the present study.

\section{$\overline{\text { Acknowledgments }}$}

This research was supported, in part, by a National Science Foundation Career Advancement Award (BNS-8709207) and a Hughes Faculty Research Award to Dr. Nancy L. Segal, the Minnesota Center for Twin and Adoption Research, and the Twin Studies Center at CSUF. The assistance of the Australian NHMRC Twin Registry is gratefully acknowledged. Dr. Richard T. Serpe offered assistance with data analysis in an earlier version of this paper, and Dr. Catherine Sanders provided information on the Grief Experience Inventory. Elena Alvarez, B.A., Samantha Etchells, M.S., Patrick Giordani, M.A., Jennifer Giordano, B.A., Dinah G. Gitlin, B.A., Karen M. Nelson, M.S., Carrie Ortega, B.A., Sarah Ream, M.A. and Steven M. Wilson, Ph.D. provided research assistance. Dr. Randy Nesse provided comments on an early version of the paper.

\section{References}

Archer, J. (1988). The sociobiology of bereavement: A reply to Littlefield and Rushton. Journal of Personality and Social Psychology, 55, 272-278.

Archer, J. (1992). Ethology and human development. Exeter: Harvester Wheatsheaf.

Archer, J. (1999). The nature of grief: The evolution and psychology of reactions to loss. London: Routledge.

Barkow, J. H. (1989). Darwin, sex and status: Biological approaches to mind and culture. Toronto: University of Toronto Press.

Baron, R. M., \& Kenny, D. A. (1986). The moderator-mediator distinction in social-psychological research: Conceptual, strategic, and statistical considerations. Journal of Personality and Social Psychology, 51, 1173-1182.

Bugen, L. A. (1977). Human grief: A model for prediction and intervention. American Journal of Orthopsychiatry, 42, 196-206.

Burnstein, E., Crandall, C., \& Kitayama, S. (1994). Some neoDarwinian rules for altruism: Weighing cues for inclusive fitness as a function of the biological importance of the decision. Journal of Personality and Social Psychology, 67, 773-789.

Buss, D. M. (1989). Sex differences in human mate preferences, evolutionary hypotheses tested in 37 cultures. Behavioral and Brain Sciences, 12, 1-49.

Buss, D. M. (1999). Evolutionary psychology: The new science of the mind. Needham Heights, MA: Allyn \& Bacon.

Chagnon, N. A., \& Bugos, P. R., Jr. (1979). Kin selection and conflict: An analysis of a Yanomamo ax fight. In N. A. Chagnon $\&$ W. Irons (Eds.), Evolutionary biology and human social behavior (pp. 213-238). North Scituate, MA: Duxbury Press. 
Crawford, C. B., Salter, B. E., \& Jang, K. L. (1989). Human grief: Is its intensity related to the reproductive value of the deceased? Ethology and Sociobiology, 10, 293-309.

Daly, M., \& Wilson, M. I. (1994). Some differential attributes of lethal assaults on small children by stepfathers versus genetic fathers. Ethology and Sociobiology, 15, 207-217.

du Toit, M., \& du Toit, S. (2001). Interactive LISREL: User's guide. Lincolnwood, IL: Scientific Software International, Inc.

Ellis, L. (1994). Research methods in the social sciences. Oxford, UK: Brown \& Benchmark, 1994.

Epstein, S. (1993). Bereavement from the perspective of cognitiveexperiential self-theory. In M. S. Stroebe, W. Stroebe, \& R. O. Hansson (Eds.), Handbook of bereavement: Theory, research, and intervention (pp. 112-125). Cambridge: Cambridge University Press.

Folkman, S. (1997). Introduction to the special section: Use of bereavement narratives to predict well-being in gay men whose partners dies of AIDS - Four theoretical perspectives. Journal of Personality and Social Psychology, 72, 851-854.

Freedman, D. G. (1979). Human sociobiology, A holistic approach. New York: Free Press.

Hamilton, W. D. (1964a,b). The genetical evolution of social behaviour. I, II Journal of Theoretical Biology, 7, 1-16, 17-52.

Hofer, M. A. (1984). Relationships as regulators: A psychobiologic perspective on bereavement. Psychosomatic Medicine, 46, 183-197.

Hofer, M. A. (1987). Early social relationships, A psychobiologist's view. Child Development, 58, 633-647.

Hofer, M. A. (1994). Hidden regulators in attachment, separation, and loss. In N. A. Fox (Ed.), The development of emotion: Regulation, biological and behavioral considerations (Monographs of the Society for Research in Child Development) 59. Chicago: University of Chicago Press.

Hofer, M. A. (1996). On the nature and consequences of early loss. Psychosomatic Medicine, 58, 570-581.

Hur, Y. M., McGue, M., \& Iacono, W. G. (1995). Unequal rate of monozygotic and like-sex dizygotic twin births: Evidence from the Minnesota Twin Family Study. Behavior Genetics, $25,337-340$.

Korchmaros, J. D., \& Kenny, D. A. (2001). Emotional closeness as a mediator of the effect of genetic relatedness on altruism. Psychological Science, 12, 262-265.

Littlefield, C. H., \& Rushton, J. P. (1986). When a child dies: The sociobiology of bereavement. Journal of Personality and Social Psychology, 51, 797-802.

Littlefield, C. H., \& Rushton, J. P. (1989). Levels of explanation in sociobiology and psychology: A rejoinder to Archer. Journal of Personality and Social Psychology, 56, 625-628.

Loehlin, J. C. (1992). Genes and environment in personality development, Vol. 2. Newbury Park: Sage Publications.

Lonnetto, R. \& Templer, D. I. (1986). Death anxiety. Washington, D.C.: Hemisphere Publishing Corporation.

Lykken, D. T., Bouchard, T. J., McGue, M., \& Tellegen, A. (1990). The Minnesota twin family registry: Some initial findings. Acta Geneticae Medicae et Gemellologiae, 39, 35-70.

Martin, J. L., \& Dean, L. (1993). Bereavement following death from AIDS: Unique problems, recations, and special needs. In M. S. Stroebe, W. Stroebe, \& R. O. Hansson (Eds.),
Handbook of bereavement: Theory, research, and intervention (pp. 317-330). Cambridge: Cambridge University Press.

McGue, M., Vaupel, J. W., Holm, N., \& Harvald, B. (1993). Longevity is moderately heritable in a sample of Danish twins born 1870-1880. Journal of Gerontology, 48, B237-B244.

Mealey, L. (2000). Sex differences: Developmental and evolutionary strategies. New York: Academic Press.

Mealey, L., \& Townsend, G. C. (1999). The role of fluctuating assymetry on judgments of physical attractiveness: A monozugotic co-twin comparison. Perspectives in Human Biology, 4, 219-224.

Mowrer, E. (1954). Some factors in the affectional adjustment of twins. American Sociological Review, 19, 468-471.

Muthen, B., Kaplan, D., \& Hollis, R. (1987). Psychometrika, 52, 431-462.

Nesse, R. M. (1991). What are emotions for? Psycholoquy, 2.

Nesse, R. M. (1994). An evolutionary perspective on substance abuse. Ethology and Sociobiology, 15, 339-348.

Nesse, R. M., \& Williams, G. C. (1994). Why we get sick: The new science of Darwinian medicine. New York: Times Books.

Nichols, R. C., \& Bilbro, W. C. (1966). The diagnosis of twin zygosity. Acta Geneticae et Statistica Medicae, 16, 265-275.

Plutchik, R. (2001). The nature of emotions. American Scientist, 89, 344-350.

Reed, M. D., \& Greenwald, J.Y. (1991). Survivor-victim status, attachment, and sudden death bereavement. Suicide and LifeThreatening Behavior, 21, 385-401.

Rubin, S. S. (1989-1990). Death of the future? An outcome study of bereaved parents in Israel. Omega, 20, 323-339.

Salmon, C. A., \& Daly, M. (1996). On the importance of kin relations to Canadian women and men. Ethology and Sociobiology, 17, 289-297.

Sanders, C. M. (1979-1980). A comparison of adult bereavement in the death of a spouse child and parent. Omega, 10, 303-322.

Sanders, C. M. (1989). Grief: The mourning after. New York: John Wiley and Sons, Inc.

Sanders, C. M., Mauger, P. A., \& Strong, P. N., Jr. (1985). A manual for the grief experience inventory. Charlotte, NC: The Center for the Study of Separation and Loss.

Sanders, C. M. (1993). Risk factors in bereavement outcome. In M. S. Stroebe, W. Stroebe, \& R. O. Hansson (Eds.), Handbook of bereavement: Theory, research, and intervention (pp. 255-267). Cambridge: Cambridge University Press.

Scarr, S. (1995). Psychology will be truly evolutionary when behavior genetics is included. Psychological Inquiry, 6, 68-71.

Segal, N. L. (1993). Twin, sibling and adoption methods: Tests of evolutionary hypotheses. American Psychologist, 48, 943-956.

Segal, N. L. (1997). Twin research perspective on human development. In N. L. Segal, G. E. Weisfeld, \& C. C. Weisfeld (Eds.), Uniting psychology and biology: Integrative perspectives on human development (pp. 145-173). Washington, D.C.: American Psychological Association Press.

Segal, N. L. (1998). Gender differences in bereavement response and longevity: Findings from the California State University Twin Loss Study. In L. Ellis \& L. Ebertz (Eds.), Males, females, and behavior: Toward biological understanding (pp. 195-212). Westport, CT: Praeger. 
Segal, N. L. (2000). Entwined lives: Twins and what they tell us about human behavior. New York: Plume.

Segal, N. L., \& Bouchard, T. J. (1993). Grief intensity following the loss of a twin and other relatives: Test of kinship genetic hypotheses. Human Biology, 65, 87-105.

Segal, N. L., \& Ream, S. L. (1998). Decrease in grief intensity for deceased twin and non-twin relatives: An evolutionary perspective. Personality and Individual Differences, 25, 317-325.

Segal, N. L., Wilson, S. M., Bouchard, T. J., Jr., \& Gitlin, D. G. (1995). Comparative grief experiences of bereaved twins and other bereaved relatives. Personality and Individual Differences, $18,511-524$

Shucter, S. R., \& Zisook, S. (1993). The course of normal grief. In M. S. Stroebe, W. Stroebe, \& R. O. Hansson (Eds.), Handbook of bereavement: Theory, research, and intervention (pp. 23-43). Cambridge: Cambridge University Press.
Sprang, M. V., McNeil, J. S., \& Wright, R. (1992-3). Grief among surviving family members of homicide victims: A causal approach. Omega, 26, 145-160.

Stevens, J. (1996). Applied multivariate statistics for the social sciences (3rd ed.). Mahwah, NJ: Lawrence Erlbaum Associates.

Stroebe, W., \& Stroebe, M. S. (1987). Bereavement and health: The psychological and physical consequences of partner loss. New York: Cambridge University Press.

Stroebe, M. S., \& Stroebe, W. (1993). The mortality of bereavement: A review. In M. S. Stroebe, W. Stroebe, \& R. O. Hansson (Eds.), Handbook of bereavement: Theory, research, and intervention (pp. 175-195). Cambridge: Cambridge University Press.

Trivers, R. L. (1985). Social evolution. Menlo Park, CA: Benjamin/Cummings.

Woodward, J. (1998) The lone twin: Understanding twin bereavement and loss. London: Free Association Books. 